\title{
LA LEUCOSIS ENZOÓTICA BOVINA: UN ASESINO SILENCIOSO'1
}

\author{
Cynthia Rebeca Monge-Rojas², Jorge Alberto Elizondo-Salazar ${ }^{2}$
}

\section{RESUMEN}

La leucosis enzoótica bovina (LEB) es una enfermedad crónica con una virulencia muy alta extendida por todo el mundo. El virus de la LEB es un retrovirus que infecta los linfocitos $B$ de la sangre y sintetiza el ADN para convertirlo en un ADN proviral por lo que el virus se embebe en el genoma del animal. Una vez infectado el animal, el virus se puede manifestar de tres maneras: individuos positivos serológicamente, pero sin signos clínicos, animales que presentan una condición llamada linfocitosis persistente donde el conteo de linfocitos es inusualmente alto y linfoma o linfosarcoma que sería la manifestación clínica de la enfermedad con tumores en distintas partes del cuerpo y se presenta en animales de más de cinco años. El conocimiento de la enfermedad permite tener un claro panorama de la situación mundial e implementar medidas sanitarias y de manejo que ayuden a prevenir el contagio y por ende disminuir su prevalencia, ya que a la fecha no se ha logrado crear una vacuna para tratar la enfermedad. Las pérdidas económicas achacadas a la LEB se reflejan especialmente en una disminución en la producción por el descarte de los animales con linfosarcomas y predisposición a la entrada de otros agentes patógenos causando otras enfermedades en el animal. Este documento tiene como objetivo presentar aspectos de importancia sobre la leucosis enzoótica bovina que, por su virulencia y prevalencia a nivel mundial, se ha convertido en una enfermedad de gran importancia sanitaria y económica en los hatos lecheros.

Palabras clave: virus, bovino, sangre, linfosarcoma, linfocitosis persistente

\footnotetext{
${ }^{1}$ Inscrito en la Vicerrectoría de Investigación de la Universidad de Costa Rica. Proyecto 737-B4-222. ${ }^{2}$ Universidad de Costa Rica, Facultad de Ciencias Agroalimentarias. Estación Experimental Alfredo Volio Mata. Cartago, Costa Rica.

Autores para correspondencia: cynthia.mongerojas@ucr.ac.cr, jorge.elizondosalazar@ucr.ac.cr (https://orcid.org/0000-0003-2603-9635).

Recibido: 18 de marzo 2019

Aceptado: 21 de mayo 2019
} 


\section{ABSTRACT}

Enzootic bovine leukosis: A silent murderer. Enzootic bovine leukosis (LEB) is a chronic disease with a very high virulence spread throughout the world. The LEB virus is a retrovirus that infects the $B$ lymphocytes of the blood and synthesizes the DNA to turn it into a proviral DNA so the virus is imbedded in the animal's genome. Once the animal is infected, the virus can manifest itself in three ways: serologically positive individuals without clinical signs, animals that have a condition called persistent lymphocytosis where the lymphocyte count is unusually high and lymphoma that would be the clinical manifestation of the disease with tumors in different parts of the body and can be found in animals over five years old. Knowing the disease, allows having a clear picture of the situation and implement sanitary and management measures that help to prevent the contagion and therefore decrease its prevalence because to date it has not been possible to create a vaccine to treat the disease. The economic losses attributed to the LEB are reflected in a decrease in production due to the discarding of animals with lymphosarcomas and predisposition to the entry of other pathogens causing other diseases in the animal. This document aims to present important aspects of enzootic bovine leukosis that, due to its virulence and prevalence worldwide, has become a disease of great health and economic importance in dairy herds.

Keywords: leukemia, virus, bovine, blood, linfosarcoma, persistent linfocitosis 


\section{INTRODUCCIÓN}

La leucosis viral bovina (LEB), leucosis enzoótica bovina, leucemia bovina o linforsarcoma bovino es una enfermedad de distribución mundial, de ocurrencia natural, crónica y contagiosa, que evoluciona en un período largo de tiempo (1 a 8 años), con el desarrollo de linfosarcomas en los animales infectados (Gutiérrez, 2010). La LEB es causada por un retrovirus que infecta y se realiza en las células blancas de la sangre (linfocitos B), e induce a una infección persistente en el animal de por vida ya que se integra en su genoma (Gutiérrez et al., 2014). La LEB es una de las infecciones más diseminadas mundialmente, aunque algunos países como Dinamarca, Reino Unido, Francia, Alemania, Bélgica, Holanda, España y los países escandinavos han logrado erradicarla a través de programas de control extremadamente estrictos que otros países están implementando con el fin de lograr los mismos resultados (Wrathall et al., 2002; Nekouei et al., 2015; Blagitz et al., 2017).

En Costa Rica se identificó por primera vez el virus de la leucosis enzoótica en ganado en 1976 y según los reportes la seroprevalencia o manifestación de la enfermedad, no ha cambiado mucho en los últimos 20 años (Romero et al., 2015). En el 2008, Beita reportó un $41 \%$ de seroprevalencia a nivel de animales y del $97,4 \%$ a nivel de hatos lecheros en nuestro país.

La LEB es caracterizada por tres estados de la enfermedad, a saber: asintomática, linfocitosis persistente (LP) y linfosarcoma, donde $30 \%$ de los animales infectados desarrollarán linfocitosis persistente después de los dos años y se quedará con ellos hasta la muerte y solamente de $0,1-10,0 \%$ presentarán linfosarcoma entre los 5 y 8 años de edad (Frie y Coussens, 2015; Andreolla et al., 2018).

Este documento tiene como objetivo comprender la leucosis enzoótica bovina que por su virulencia y prevalencia a nivel mundial se ha convertido en una enfermedad de gran importancia sanitaria y económica en los hatos lecheros. 


\section{El virus}

El virus de la LEB es un retrovirus, es decir es un tipo de virus donde su ARN inserta una copia de su genoma dentro del ADN del huésped convirtiendo por medio de la transcriptasa inversa el $A R N$ en $A D N$, entonces el retrovirus integra su ADN viral en el ADN del huésped lo que permite que el retrovirus se replique y sea prácticamente imposible de tratar. Este retrovirus pertenece a la familia retrovirae, subfamilia Orthoretrovirinae, del género Deltaretrovirus, conocido por tener un retrovirus tipo $C$, al ser un retrovirus posee una reverso-transcriptasa que va a sintetizar una copia de ADN (ADN proviral; que es el ADN resultante de la transcripción inversa del ARN de la LEB que se integra en el ADN celular del huésped) a partir del ARN viral (Baruta et al., 2011). Lo que esto significa es que el virus se integra al genoma del animal lo que lo hace persistente y se va a prolongar durante toda la vida del animal.

Si bien es cierto el virus de la LEB puede afectar un número grande de animales en el establecimiento, son pocos los que desarrollan los síntomas clínicos. Sin embargo, son precisamente esos animales que no desarrollan los signos clínicos los que constituyen un peligro para el resto de la población, ya que como se mencionó anteriormente son portadores del virus de por vida (Kettmann et al., 1980; Brenner et al., 1989 y Romero et al., 2015). Por lo tanto, el conocimiento del estado actual del hato se convierte en un factor de vital importancia con el fin contener la prevalencia del virus en el hato, y el manejo de las secreciones y excreciones de los animales infectados debe ser meticulosa.

El comportamiento y trasmisión del virus hace que la situación actual sea muy variable en función de los países y del manejo o importancia que le den a la enfermedad, incluso dentro del mismo país las tasas de infección pueden ser muy diferentes de una región a otra y de un hato a otro. En muchos países la infección se relaciona con la importación de reproductores pues muchas veces son seropositivos y llegan a infectar el hato (Toma et al., 1990). 


\section{Transmisión}

Debido a que el virus infecta los linfocitos $B$ en sangre, el mecanismo principal para la transmisión de LEB es por medio de células sanguíneas, que contengan linfocitos $B$ infectados con ADN proviral (ADN infectado), por lo tanto cualquier tipo de secreción y excreción van a ser factores potenciales de contagio.

El virus se alberga en la fracción celular de la sangre y la viremia o cantidad mínima de sangre infectada para transmitir la enfermedad es de $1 / 100^{\circ}$ de gota (Toma et al., 1990), y esta puede ser infecciosa hasta 15 días antes de aparecer los anticuerpos séricos. La transmisión entonces puede ocurrir en una variedad de maneras, entre las que se pueden citar:

- La transmisión horizontal o directa; puede ser natural debido a la exposición de animales sanos con la sangre $u$ otros fluidos biológicos conteniendo linfocitos infectados de animales enfermos (Beita, 2008; Benavides et al., 2012). Una de las principales formas de transmisión directa es la transmisión iatrogénica, que es la forma más común de contacto y está directamente relacionada con el hombre y las prácticas sanitarias o de manejo implementadas en las explotaciones ganaderas. El uso de equipo de descorne, agujas hipodérmicas, instrumentos quirúrgicos o cualquier otro equipo en varios animales sin desinfectar debe de evitarse, ya que son fuentes de contagio debido a que en todos estos procedimientos existe la exposición a pequeñas o grandes cantidades de sangre (Gutiérrez, 2010).

- La transmisión mecánica por grandes moscas o insectos hematófagos que al picar estarían transfiriendo el virus de un animal a otro (Perino et al., 1990; Toma et al., 1990; Beita, 2008; Benavides y Trujillo, 2012).

- La transmisión vertical o prenatal de la madre al feto antes del nacimiento o en el momento del parto. La transmisión intrauterina por medio de la placenta se considera infrecuente, aunque no imposible ya que se han encontrado animales recién nacidos positivos incluso antes de consumir calostro de vacas infectadas, donde un $4 \%$ de los terneros infectados en el útero eran crías de vacas con linfocitosis persistente o linfosarcoma (Piper et al., 1979; Toma et al., 1990; Beita 2008; Gutiérrez, 2010; Meas et al., 2002; Benavides y Trujillo, 2012). Sin embargo, es importante mencionar que Gutiérrez et al. (2014a), encontraron que los terneros infectados en la primera semana de edad podrían jugar un papel importante en la transmisión del virus a animales 
susceptibles, lamentablemente en el estudio realizado no pudieron determinar la fuente de contagio de los terneros.

- La ingestión de calostro y leche de vacas infectadas. A pesar de que el rol de la leche en la transmisión de LEB ha sido muy estudiado ya que el virus y las células se han encontrado en la leche y el calostro de vacas infectadas, en condiciones naturales no se ha comprobado la infección vía oral a pesar de que algunos investigadores señalan a la leche como fuente de infección, debido a la presencia de partículas virales, material infeccioso y ADN proviral (Gutiérrez, 2010). Ferrer y Piper (1981), demostraron que en caso de que exista transmisión de LEB por medio de la leche o el calostro, esta juega un papel secundario en la diseminación de la enfermedad.

Es importante tener en cuenta que la susceptibilidad de los terneros a la infección estaría modificada por la presencia de anticuerpos calostrales maternos contra LEB que iría disminuyendo con el tiempo (Gutiérrez, 2010; Gutiérrez et al., 2015). Diversos estudios utilizan como medida para disminuir la transmisión temprana de la enfermedad el consumo de calostro de madres negativas seguido de una alimentación con leche de vacas negativas, utilización de leche pasteurizada y/o reemplazador de leche (Ferrer y Piper, 1981; Lassauzet et al., 1989; Dimmock et al., 1991).

- Esperma: en condiciones normales no existe evidencia de ser virulento; sin embargo, en presencia de lesiones traumáticas o inflamatorias podría existir contagio por medio de los linfocitos infectados (Miller y Van der Maaten, 1979; Kaja y Olson, 1982; Straub, 1982; Dus Santos et al., 2007). En 2002, Choi et al., reportaron que si el semen es recolectado adecuadamente, no debería constituirse en una fuente de infección, lo que los investigadores concluyeron es que en los casos en que el contagio se atribuyó al semen, se debió a la presencia de sangre en este, generada a la hora de la recolección o fue debido a algún tipo de enfermedad inflamatoria pero no del semen per se (Kahrs et al., 1980; Kaja y Olson, 1982; Wrathall et al., 2006)

- La orina, heces, saliva, secreciones nasales y oculares podrían jugar un pequeño papel en la transmisión de LEB cuando se encuentran contaminadas con linfocitos infectados con el ADN proviral ya que al encontrarse el virus presente en las células blancas de la sangre de los bovinos infectados incluso en pequeñas cantidades de sangre transferida entre animales puede ser foco de contaminación (Nekouei et al., 2015). 
Es de suma importancia tener claro que este virus va a condicionar su virulencia o capacidad de causar la enfermedad en la presencia de linfocitos infectados en una secreción o excreción, esta podría también ser aumentada en caso de lesiones inflamatorias en los animales infectados, por lo tanto aquellas secreciones o excreciones que no contengan linfocitos infectados no presentan riesgo de contagio.

\section{Diagnóstico}

Al contrario de muchas otras enfermedades, en el caso de la LEB los animales positivos al virus y los que presentan linfocitosis persistente solamente pueden ser diagnosticados a través de técnicas en el laboratorio, mientras que los animales que presentan linfosarcoma, pueden ser fácilmente diagnosticados por el médico veterinario.

La manera de detectar los animales infectados con el virus de la Leucosis es determinando la presencia de anticuerpos en sangre, debido a que los animales infectados con el virus desarrollan anticuerpos específicos (Benavides y Trujillo, 2012). El ganado infectado con LEB produce anticuerpos contra las proteínas virales llamadas gp51 y p24. Estos anticuerpos pueden ser detectados a través de un número de pruebas de laboratorio, y la aparición de anticuerpos específicos para las proteínas virales indica que el animal está infectado (Baruta et al., 2011; Barez et al., 2015).

Es de suma importancia utilizar pruebas de laboratorio confiables y con alta sensibilidad ya que los programas de control y erradicación del virus de la leucosis se van a basar en la detección de los animales seropositivos, para la toma de decisiones de eliminación, segregación o manejo de animales debido a que el diagnóstico de los animales infectados o con linfocitosis persistente solamente se puede realizar en el laboratorio (Dolz y Moreno, 1999; Dolz et al., 2015)

Los análisis oficiales y aprobados por la Organización Mundial de Sanidad Animal comúnmente utilizados para detectar anticuerpos de LEB incluyen ensayo enzimático ligado inmunoabsorbente (ELISA) y la inmunodifusión en gel de agar (IGDA) (Dolz y Moreno, 1999; Toma et al., 1990; Gutiérrez et al., 2009; Andreolla et al., 2018). Es importante mencionar que, a pesar de sus falencias, la técnica ELISA ha sido considerada como la más adecuada para el diagnóstico y programas de control, especialmente porque presenta mayor sensibilidad que el IGDA que por su baja sensibilidad podría dejar pasar 
infecciones en hatos clínicamente normales y a pesar de haber sido por mucho tiempo el análisis utilizado por su simplicidad y confiabilidad (Dolz et al., 2015).

La infección con LEB también puede diagnosticarse mediante la detección del ADN viral en las células infectadas, por lo general por reacción en cadena de la polimerasa (PCR) en la evaluación de células de la capa leucocitaria de la sangre anticoagulada (González et al., 2001; Baruta et al., 2011). Si bien no se utiliza tan comúnmente como la prueba de anticuerpos debido a su alto costo y complejidad, por su sensibilidad el PCR puede ser útil para confirmar la infección en el ganado vacuno con anticuerpos para LEB y también para evaluar animales jóvenes (Choi et al., 2002).

\section{Signos clínicos}

Son muy pocos los animales que desarrollan la fase clínica de la enfermedad por lo que la mayoría de los casos (95\%) no presentan ninguna alteración en su estado de salud y puede ser tan productivo como un animal negativo (Ferrer, 1979).

La infección del ganado con LEB tiene tres resultados posibles:

Una mayoría de los animales se vuelven persistentemente infectados con el virus, pero permanecen clínicamente normales (Gutiérrez et al., 2009).

Aproximadamente uno de cada tres vacas infectadas (30-40\%) desarrollan un trastorno llamado linfocitosis persistente, en el que tienen números anormalmente altos de linfocitos en la sangre, pero no muestran la enfermedad clínica (Ferrer et al., 1978; Gutiérrez et al., 2014b; Barez et al., 2015). Esta linfocitosis además se caracteriza por la presencia de células linfocitarias inmaduras o atípicas en sangre, con un incremento en el número absoluto de los linfocitos $B$ circulantes en sangre periférica, incluso más abundantes que los linfocitos T causando un cambio inverso en la proporción B/T (Gutiérrez et al., 2014b). A pesar de que la linfocitosis persistente es una característica subclínica, estos animales podrían sufrir problemas con el sistema inmunológico evidenciado por infecciones oportunistas como la mastitis (Suzuki et al., 2013), lo que podría provocar susceptibilidad a otras infecciones y después de algunos años desarrollar los tumores característicos de la leucosis, ya que la probabilidad de desarrollar tumores es mayor en animales con 
concentraciones incrementadas de linfocitos circulantes, por lo que la linfocitosis persistente se puede considerar como una fase pre-tumoral (Gillet et al., 2007).

Solamente una pequeña fracción de las vacas infectadas (menos del 5\%) va a desarrollar linfosarcoma que es un cáncer del tejido linfático. El linfosarcoma generalmente se desarrolla entre las edades de 5 y 8 años, y es poco frecuente en los animales de menos de dos años de edad ya que el período de incubación del virus puede ser de 2 a 8 años (Gutiérrez et al., 2014b; Barez et al., 2015; Frie y Coussens, 2015; Romero et al., 2015). Los signos clínicos observados en el ganado con linfosarcoma van a depender de la ubicación del tumor en el cuerpo del animal. Algunas vacas muestran hinchazón, otras pueden mostrar trastornos digestivos, pérdida de peso o dificultad para respirar, debido a tumores internos.

Resultados de estudios que evalúan el efecto del virus sobre la producción láctea han sido contradictorios por lo que no se puede asegurar el efecto de la LEB sobre la producción. Sin embargo, los estudios que se basan en evaluar el efecto del virus sobre los parámetros reproductivos han sido un poco más concluyentes. Romero et al. (2015) encontraron mayor incidencia del virus en vacas de primera lactancia $(23,5 \%)$, coincidiendo con otros investigadores (Beita, 2008) en que el contagio o prevalencia del virus aumenta conforme los animales entran en la fase productiva probablemente debido a que existe mayor contacto con animales infectados y mayor manipulación por parte del personal (transmisión iatrogénica).

Además, se han encontrado diferencias significativas de 21 días en el intervalo entre partos de animales seronegativos al compararlos con seropositivos; igualmente las vacas seropositivas requirieron de más servicios por concepción, lo que indica que el virus de la leucosis podría comprometer la reproducción en los animales contagiados (Romero et al., 2015).

En el 2015, un grupo de investigadores estudiaron el perfil sanguíneo de vacas infectadas con o sin linfocitosis persistente y encontraron que existen implicaciones del virus al compararlas con vacas saludables al observar la disfunción de los monocitos y neutrófilos ya que los animales con el virus presentan mayor susceptibilidad a infecciones secundarias (Blagitz et al., 2015).

La LEB podría ser confundida con la leucosis juvenil o la leucosis cutánea del adulto por ser afecciones leucósicas, pero se trata de enfermedades completamente distintas (Toma et al., 1990). 


\section{Lesiones}

El ganado con linfocitosis persistente tiene números anormalmente altos de linfocitos en la sangre y recuento altos de leucocitos (Barez et al., 2015).

En el caso de la fase tumoral, los linfosarcomas pueden ocurrir en muchos sitios del cuerpo y en muchos casos, múltiples tumores están presentes en un solo animal. Los tumores tienen una apariencia de color amarillo o marrón en los órganos afectados y se pueden ver ya sea en forma de nódulos o un infiltrado difuso de células tumorales dentro de los órganos (Heeney, 1992).

En algunos casos, los ganglios linfáticos superficiales aumentan de tamaño y son visibles o se pueden palpar debajo de la piel. Protuberancias aplanadas en la piel es otra forma de la enfermedad, así como tumores en corazón, abomaso, útero, riñón, bazo, hígado y médula espinal (Ferrer, 1980).

La forma entérica o aquella relacionada con el aparato digestivo de los animales es otra de las manifestaciones más comunes de la enfermedad, y en estos casos el animal presenta problemas digestivos, anemia y pérdida de peso. En el examen postmortem se observa un engrosamiento de la mucosa del abomaso y de los ganglios asociados al tracto digestivo, en el caso de los tumores en la médula espinal el animal presenta cojeras, debilidad y finalmente el síndrome de la vaca caída sin estar asociados a enfermedades metabólicas, una vez manifestada la enfermedad en su forma clínica las afecciones y complicaciones en los órganos esenciales provocan la muerte del animal en 1 a 6 meses después de la aparición de los linfosarcomas (Toma et al., 1990; Willems, 2000; Florins, 2007; Gutiérrez, 2010).

\section{Tratamiento y control de la enfermedad}

A la fecha no existe un tratamiento para la leucosis bovina; sin embargo, han existido y existen muchos esfuerzos por encontrar una vacuna (Gutiérrez et al., 2014b; Barez et al., 2015), que sería la única solución aparente para lograr contener el contagio de esta enfermedad. La vacuna debe ser no-infecciosa, no-oncogénica (que no produzca 
tumores/cáncer) y capaz de neutralizar el virus (Gutiérrez, 2010). Los intentos fallidos de las vacunas evaluadas en el pasado se han dado a la hora de probarlas en condiciones de campo, mayormente por la falta de estimulación del sistema inmune del animal infectado, por lo que en estos momentos se cree que utilizar un clon atenuado del virus pero competente a la hora de replicarse, que proteja los hatos contra la LEB sería la opción a probar (Barez et al., 2015).

Por lo tanto, en estos momentos el control y erradicación va a depender de la edad de los animales infectados, el porcentaje de animales infectados en el hato, la infraestructura y prácticas de manejo en el establecimiento.

Entre los procedimientos de manejo recomendados para minimizar la transmisión de LEB se pueden mencionar:

- El uso de agujas desechables y no utilizar la misma aguja para inyecciones en múltiples animales.

- Desinfección de equipo de tatuaje y los instrumentos quirúrgicos entre los animales.

- El tratamiento con calor o pasteurización del calostro.

- Pasteurización de la leche y/o uso de reemplazador lácteo.

- Control de moscas que pican (moscas de caballos y las moscas del venado).

- Eliminación de los animales que tienen anticuerpos contra el virus especialmente cuando la tasa de infección es baja (menos de 10\%).

- La comprobación periódica de todos los animales, control serológico cada tres meses con el fin de ir descartando animales positivos.

- En el caso de una tasa de infección alta (más de 10\%) se deben establecer un manejo sanitario estricto con el fin de evitar la transmisión horizontal.

- También es aconsejable comprar solamente animales con resultado negativo para agregar a su hato.

Cuando la decisión ha sido limpiar el hato eliminando animales positivos con el fin de declararse libre de leucosis, se deben hacer pruebas serológicas en los animales negativos, una vez que estos han dado negativo en dos pruebas consecutivas el establecimiento se puede declarar libre de leucosis y a partir de ese momento se deberá realizar un seguimiento serológico anual (Baruta et al., 2011). 
Lamentablemente disminuir la prevalencia de la Leucosis puede tomar años y si no se realiza adecuadamente puede ser un trabajo en vano.

\section{Importancia económica de la enfermedad}

La LEB puede llegar a provocar pérdidas económicas difíciles de calcular. Las pérdidas directas están relacionadas a las pérdidas en producción por causa de la enfermedad (disminución en la producción láctea, muerte, descarte de animales), tratamientos y costos de diagnóstico de la enfermedad (Nekouei et al., 2015).

A pesar que no se ha logrado encontrar evidencia contundente de que los animales positivos al virus producen igual o menor cantidad de leche que los negativos, las pérdidas económicas por la disminución en la producción de leche se le podrían achacar al descarte y/o reemplazo de los animales antes de lo previsto debido a la presencia de linfosarcomas. La razón principal por la que aún no se ha logrado medir el impacto negativo de la leucosis en la producción y reproducción se debe a que los animales que desarrollan linfosarcomas lo hacen hasta los 5-8 años de edad por lo que el efecto se podría catalogar como un efecto de longevidad ya que la mayoría de hatos productivos manejan un promedio de vida menor entre 3,5-4,0 partos, es decir, 5,5-6,0 años de edad.

El verdadero impacto económico asociado a la LEB está asociado a las restricciones de comercialización entre animales vivos, semen y embriones (Gutiérrez et al., 2009). En muchos casos o países, entre las exigencias de compra se pide que tanto el semen, embriones y animales en pie vengan de fincas certificadas como libres de la enfermedad, especialmente cuando se trata de países europeos, ya que han invertido muchísimos recursos en erradicar la enfermedad en estas áreas.

Así que la prevención de la LEB aunque costosa, provee una ventaja competitiva, ya que convierte al hato en un hato libre de leucosis que lo posiciona y permite incursionar en el mercado mundial. Porque a pesar de no ser una barrera sanitaria para la comercialización de ganado le confiere un valor agregado al animal, semen o embriones. 


\section{CONSIDERACIONES FINALES}

La Leucosis Enzoótica Bovina es una enfermedad con una alta prevalencia que se encuentra diseminada por todo el mundo. El hecho que la mayoría de estudios se realizan en hatos lecheros se explica debido a que son las explotaciones que generan mayores factores de riesgo de contagio debido a la cantidad de manejo y manipulación que requieren. Después de entender un poco la enfermedad y su comportamiento se puede concluir que en estos momentos la única manera de controlarla y llegar a su erradicación en los hatos es por medio de controles sanitario estrictos, implementación de las buenas prácticas pecuarias, identificación, aislamiento y/o sacrificio de los animales positivos.

Tanto Costa Rica como todos los demás países con prevalencia del virus, deberían implementar medidas de control y reporte obligatorio como en el caso de la tuberculosis y brucelosis, con el fin de disminuir o erradicar la enfermedad para reducir las pérdidas ocasionadas a los productores ya que la fase clínica es muy avanzada y además de que la muerte de los animales es inminente y han sido una fuente de contacto importante para el hato.

Establecer un protocolo sanitario de control de la LEB, beneficia al productor ya que puede decidir sacrificar a los animales positivos antes de que lleguen a la fase clínica donde no van a obtener ganancias, pues la presencia de linfosarcomas en los animales es motivo de castigo en el matadero.

Los países que logran erradicar la LEB consiguen un valor agregado a la hora de ingresar al comercio internacional, especialmente si se quiere comercializar reproductores, embriones y semen.

En general, se puede decir que la LEB es un asesino silencioso, que puede estar presente a lo largo de la vida del animal y una vez que se manifiesta clínicamente con la aparición de linfosarcomas el curso de la enfermedad es muy rápido y en unos pocos meses el animal muere. Esto hace especialmente necesario redoblar esfuerzos en la creación de la vacuna mientras se trata de controlar cualquier fuente de contagio por insignificante que parezca. 


\section{LITERATURA CITADA}

Agresti, A., W. Ponti, M. Rochi, R. Menveri, A. Marozzi, D. Cavalleri, E. Peri, G. Poli, y E. Ginelli. 1993. Use of polymerase chain reaction to diagnose bovine leukemia virus infection in calves.Am. J. Vet. Res. 54:373-376.

Andreolla, A.P., L.M. Scherr-Erpen, R. Frandoso, y L.C. Kreutz. 2018. Development of an indirect Elisa based on recombinant capsid protein to detect antibodies to bovine leukemia virus. Brazilian Journal of Microbiology 49 (Suppl. 1): 68-75.

Barez, P-Y., A. Brogniez, A. Carpentier, H. Gazon, N. Gillet, G. Gutiérrez, M. Hamaidia, J.R. Jacques, S. Perike, A.N. Sriramareddy, N. Renotte, B. Staumont, M. Reicher, K. Trono, y L. Willems. 2015. Recent advances in BLV research Viruses 7: 60806088.

Baruta, D.A., S.M. Ardoino, J.L. Brandan, R.E. Sosa, E.L. Mariani, y E.M. Albretch. 2011. Leusosis bovina enzoótica. Ciencia Veterinaria 13 (1): 9-16.

Beita, G. 2008. Epidemiología de la leucosis enzoótica bovina en hatos lecheros especializados. Tesis de licenciatura. Universidad Nacional, Heredia, C.R 53p.

Benavides-Benavides, B., y L.M. Laverde-Trujillo. 2012. Virus de leucosis bovina: un enemigo silencioso. Journal of Agriculture and Animal Science 1(1): 52-61.

Blagitz, M.G., F.N Souza, C.F. Batista, L.F.F. Azevedo, E.M.R. Sánchez, S.A. Diniz, M.X. Silva, J.P. Haddad, y A.M.M.P. Della-Libera. 2017. Immunological implications of bovine leulemia virus infection. Research in Veterinary Science 114: 109-116.

Brenner, J., M. Van Haam, D. Savir, y Z. Trainin. 1989. The implication of LEB infection in the productivity, productive capacity and survival rate of dairy cow. Vet. Inmmunopathol 3: 299-305.

Choi, K.Y., D. Monke, y J.L. Stott. 2002. Absence of bovine leucosis virus in semen of seropositive bulls. J. Vet. Invest .14: 403-406.

Dimmock, C.K., Y.S. ChunG, y A.R. Mackenzie. 1991. Factors affecting the natural transmission of bovine leukemia virus infection in Queensland dairy herds. Aust. Vet. J. 68: 230-233. 
Dolz, G., y E. Moreno. 1999. J. Vet. Med. B. Comparison of agar gel immunodiffusion test, enzyme-lynkedimmunosorbet assay and western blotting for the detection of LEB antibodies 46: 551-558.

Dolz, G., F. Huijsen, C. Jiménez, y L.L Rodríguez. 2015. Evaluation of a voluntary control program for the detection of bovine leukemia virus antibodies based on agar gel immunodiffusion test in dairy farms in Costa Rica. Open Journal of Veterinary Medicine 5: 229-233.

Dus Santos, M.J., K. Trono, I. Lager, y A. Wigdirivitz. 2007. Development of a PCR to diagnose BLV genome in frozen semen samples. Vet. Microbiol. 119: 10-18.

Ferrer, J.F. 1979. Bovine leukosis: natural transmission and principles of control. J. Anim. Vet. Med. Assoc. 175: 1281-1286.

Ferrer, J.F., y C.E. Piper. 1981. Role of colostrum and milk in the natural transmission of the bovine leukemia virus. Cancer Research. 41: 4906-4909.

Frie, M.C. y P.M. Coussens. 2015. Bovine leukemia virus: A major silent threat to proper immune responses in cattle. Veterinary Immunology and Immunopathology 163: 103-114.

Gillet, N., A. Florins, M. Boxus, C. Burteau, A. Nigro, F. Vandermeers, H. Balon, A.B. Bouzar, J. Defoiche, y A. Burny. 2007. Mechanisms of leukemogenesis induced by bovine leukemia virus: Prospects for novel anti-retroviral therapies in human. Retrovirology 4: 18.

González, E.T., G.A. Oliva, A. Valera, E. Bonzo, M. Licursi, y M.E. Etcheverrigaray. 2001. Leucosis enzoótica bovina: evaluación de técnicas de diagnóstico (ID, ELISA-i, WB, PCR) en bovinos inoculados experimentalmente. Analecta Veterinaria 21(2): 12-20.

Gutiérrez, G. 2010. Estudio de la dinámica de la infección perinatal con BLV en un rodeo de tambo con alta prevalencia. Tesis doctoral. Universidad de Buenos Aires, Argentina 182pp.

Gutiérrez, G., I. Alvarez, N. Fondevia, R. Politzki, M. Lomónaco, S. Rodríguez, M.J. Dus Santos, y K. Trono. 2009. Detection of bovine leukemia virus specific antibodies using recombinant p24-ELISA.VeterinaryMicrobiology 137: 224-234. 
Gutiérrez, G., I. Alvarez, R. Merlini, F. Rondelli, y K. Trono. 2014a. Dynamics of perinatal bovine leukemia virus infection. BMC Veterinary Research10: 82-86.

Gutiérrez, G., M. Lomonaco, I. Alvarez, y F. Fernández. 2015. Characterization of colostrom from dams of BKV endemic dairy herds. Veterinary Microbiology 177: 366-369.

Gutiérrez, G., A. Rodríguez, A. Brogniez, N. Gillet, R. Golime, A. Burny, J.P. Jaworski, I. Alvarez, L. Vagnoni, K. Trono, y L. Willems. 2014b. Vaccination against dretroviruses: The bovine leukemia virus paradigm. Viruses 6: 2416-2427.

Kahrs, R., E.P.J. Gibbs, y R.E. Larsen. 1980. The search for viruses in bovine semen, a review. Theriogenology 14(2): 151-165.

Kaja, R.W., y C. Olson. 1982. Non-infectivity of semen from bulls infected with bovine leukosis virus. Theriogenology 18(1): 107-112.

Kettman, R., Y. Cleuter, M. Mammerickx, M. Meunir, G. Benrnardi, A. Burny, y H. Chantrenne. 1980. Genomic integration of bovine leukemia provirus: comparison of persistent lymphocytosis with the lymph node tumor form of enzootic bovine leucosis. Proc. Nact. Acad. Scie. 77:257-258.

Kobayashi, S., A. Hidano, T. Tsutsui, T. Yamamoto, Y. Hayama, T. Nishida, N. Muroga, M. Konishi, K. Kameyama. y K. Murakami. 2014. Analysis of risk factors associated with bovine leukemia virus seropositivity within dairy and beef breeding farms in Japan: a nationwide survey. Research in Veterinary Science 96: 47-53.

Lassauzet, M.L., W.O. Johnson, M.C. Thurmoun, y F. Stevens. 1989. Protection of colostral antibodies against bovine leukemia virus infection in calves on California dairy. Can. J. Vet. Res. 53: 424-430.

Meas, S., T. Usui, K. Ohashi, C. Sugimoto, y Onuma. 2002. Vertical transmission of bovine leukemia virus and bovine immunodeficiency virus in dairy cattle herds. Veterinary Microbiology 84: 275-282.

Miller, J.M., y M.J. Van der Maaten. 1979. Infectivity test secretions and excretions from cattle infected with bovine leukemia virus. J. Natl. Cancer Inst. 62: 425-428.

Murakami, K., S. Kobayashi, M. Konishi, K. Kameyame, T. Yamamoto. Y T. Tsutsui. 2011. Veterinary Microbiology 148: 84-88. 
Nekouei, O., H. Stryhn, J. VanLeeuwen, D. Kelton, y P. Hanna. 2015. Predicting withinherd prevalence of infection with bovine leukemia virus using bulk-tank milk antibody levels. Preventive Veterinary Medicine 122: 53-60.

Nekouei, O., J. VanLeeuwen, J. Sanchez, D. Kelton, A. Tiwari, y G. Keefe. 2015. Herdlevel risk factors for infection with bovine leukemia virus in Canadian dairy herds. Preventive Veterinary Medicine 119: 105-113.

Ohno, A., S. Takeshima, Y. Matsumoto, y Y. Aida. 2015. Risk factors associated with increased bovine leukemia virus proviral load in infected cattle in Japan from 2012 to 2014. Virus Research 210: 283-290.

Perino, L.J., R.E. Wright, K.L. Hoppe, y R.W. Fulton. 1990. Bovine leucosis virus transmission with mouthparts from Tabanus abactor after interrupted feeding. Am, J. Vet. Res. 51: 1167-1169.

Piper, C.E., J.F. Ferrer, D.A. Abt, y R.R. Marshak. 1979. Postnatal and premayal transmission of the bovine leukemia virus under natural conditions. J. Natl. Cancer. Inst. 62 (1): 165-168.

Romero, J.J., G. Dávila, G. Beita, y G. Dolz. 2015. Relación entre el estado serológico a leucosisbovinaenzoótica y parámetros reproductivos en hatos lecheros especializados de Costa Rica. Agronomía Costarricense. 39(2): 7-18.

Straub, O.C. 1982. Transmission studies from leukotic cattle to sheep using secretions, excretions, breath and skin scrapings. Curr. Top. Vet. Med. Anim. Scie. 15: 299309.

Toma, B., M. Eloit, y M. Savey. 1990. Las enfermedades animales por retrovirus: leucosis bovina enzoótica, anemia infecciosa de los équidos, artritis/encefalitis caprina. Rev. sci. tech. Off. int. Epiz. 9(4): 1077-1119.

Wrathall, A.E., H.A. Simmond, y A. Van Soom. 2006. Evaluation risks of viral transmission to recipients of bovine embryos arising from fertilization with virus-infected semen. Theriogenology 65: 247-274.

Yeon-Choi, K., D. Monke, y J.L. Stott. 2002.Absence of bovine leukosis virus in semen of seropositive bulls. J. Vet Diagn Invest. 14: 403-406. 